\title{
Course Design in the Digital Age: Learning Through Interaction With News-Based Materials
}

\author{
Tim Marchand \\ J. F. Oberlin University, Tokyo, Japan \\ Benedict Rowlett \\ Chuo University, Tokyo, Japan
}

\begin{abstract}
The use of digital media as a mode of delivering course materials has become increasingly common in the field of language education. The aim of language educators has therefore been to discover suitable ways of using digital media to enable learners to engage with materials effectively and enhance their learning experience. This paper describes a collaborative syllabus between teachers at two Japanese universities which shares the same mode of delivery: a website of news-based materials. Students are asked to read an authentic and current news story each week and, after a classroom session, write their reactions to the story by adding their comments on the website. By using an online mode of delivery, students are motivated to build their confidence in expressing themselves in English away from the classroom and begin to engage fully with the course materials as their opinions become topics in the developing online discussions.
\end{abstract}

Recent years have seen a significant rise in the proliferation of digital media in our lives. This is also true of the classroom, where teachers are now able to use a vast array of material from the Internet as an alternative to more traditional teaching tools such as board work and handouts. However, as Chun (2008) pointed out, the use of such technology should not be considered a methodology in itself. In fact, Blake (2008) envisaged that language teaching will change not because of technology but as a result of teachers "rethinking what they do" when incorporating technology into their syllabi and lessons (p. 8). There has therefore been a great deal of experimentation and research by teachers into using digital media and materials as an aid to language learning (Arena \& Jefferson, 2008; Carney, 2007; Johnson, 2004, Kung \& Chuo, 2002). Significant to this is what Alm (2006) has identified as the recent shift from using the Internet as a repository of reference materials to using it for blogging and social networking, modes of communication that many language learners use in their daily lives. This has exciting implications for the process of language learning, now seen by most as a more personal, proactive, conscious, and cognitive endeavor (Brown, 2006). As a result, Erbaggio, Gopalakrishnan, Hobbs, and Liu (2010) consider digital technology to be an effective way of connecting with the current population of students by communicating with them in "their own language." This, in turn, can have an impact on their motivation and engagement. With this in 
mind, for teachers who are charged with creating their own courses, utilizing digital technology and materials in their classes has become a valuable component of the course design process.

The nature of the Japanese higher education context means that course and materials design is an ongoing concern of teachers. Most Japanese higher education institutions require all students to have one or two years of compulsory language study (Butler \& lino, 2005). While some of these institutions have well-established language programs in place that aim to provide a general course in English to students in all departments, many require individual teachers to design and implement appropriate courses for single departmental classes that they are asked to teach from year to year (Marchand, 2011). Often such institutions provide nothing more than a course title and a general idea of student level. Teachers are therefore responsible for making most of the major decisions about the content of the course, including materials selection and student assessment. Faced with this situation, the authors of this paper have collaborated to design and teach a language course concurrently to two classes at two universities in the Tokyo area. The authors decided to use a website updated weekly with current news stories as a central feature of the course. This would function as a medium for presenting lesson content and for students to interact with the weekly topic and each other by adding their comments and opinions. The authors planned to examine the results of student interaction with the course content and to discover students' opinions and reactions to using the online materials. This paper will therefore look at some of the decisions that went into the course design process and explain the choice and use of digital materials. It will then present and comment on a few examples of student use of the website. Finally it will conclude by discussing the results of a survey that asked students about their opinions of the course and their interaction with the materials online.

\section{Course Design Process}

The course has its origins in a syllabus designed for a university course in Current Affairs English by Marchand (2011). Through a process of decision-making, informed by the components of Graves's (2000) course design framework (defining context, assessing needs, developing materials, etc.), Marchand created a course using news articles as the main content of the lessons. The success of the course, as reflected in the positive feedback from students (Marchand, 2011), clarified that the main elements of the current affairs course would be very suitable for other university classes. The authors therefore began to meet regularly before the start of the academic year to discuss ways in which they could collaborate on the writing of materials and the administration of the course for their respective classes. What follows is an outline of the main features of the course with reference to the decisions made during the course design process regarding teaching context, course content and materials, and mode of delivery.

\section{Teaching Context}

Both authors teach compulsory English classes at two large private universities in the Tokyo area. Three classes of non-English majors were involved in the study for a total of 62 students; one class was from the commerce department of one university and two classes were from the law department of the other. Initial information provided by the universities indicated that the student level would be intermediate to advanced, based on their English test scores (ranging on the TOEIC test from approximately 400 to 900) or previous experience of study or living overseas. The authors therefore anticipated that the students would have enough English to cope with challenging materials. However, based on previous teaching experiences and beliefs (Graves, 2000), the authors were concerned that students who had not selected English as their major would be more difficult to motivate. In addition, there was the widely documented 
problem of Japanese student reticence to speak out in class and engage fully with the learning process (Anderson, 1993; Doyon, 2000; Marchand, 2012; Williams, 1994). Consequently, it was imperative that the content of the lessons engage student interest and keep students motivated for the duration of the two-semester course. As a result of the success indicated by Marchand's (2011) study, it was decided to continue to use authentic contemporary news articles to encourage student curiosity with the events of the outside world, or in other words, to take them beyond the more didactic style they may have already experienced in the traditional language learning classroom. This approach is also supported by previous studies into the benefits of using authentic materials (Rogers \& Medley, 1998) which claim that contact with authentic language is, as Lahuerta Martínez (2003, p. 134) describes, "a discriminating factor in the acquisition of competence in the foreign language" enabled through communication based on the conveyance and perception of meaningful information.

\section{Course Content and Materials}

The core of each lesson was therefore an authentic news article, condensed and adapted from news websites such as BBC news or CNN by each teacher in turn every week. The news stories were chosen for both their inherent interest and currency: each story was about an event that had happened in the previous week and would possibly be familiar to students who followed events in the news. The structure of each lesson is represented in the table below and in the example materials in Appendix A. To maximize student interaction in class and facilitate language learning, as well as provide a way of dealing with the difficulties imposed by the use of authentic materials (Erbaggio, Gopalakrishnan, Hobbs, \& Liu, 2010), a communicative approach using a task cycle was adopted, based on Marchand's (2011) previous syllabus (see Table 1). While the first stages of the task cycle are carried out in the classroom, it was the aim of the authors to facilitate an environment where students could extend their interaction with the materials and create a context where further learning could take place. The opportunities afforded by the use of digital media therefore became a central part of the design and administration of the course.

\section{Table 1}

\section{Lesson Cycle}

\begin{tabular}{|l|l|l|}
\hline Focus on meaning & Warm up & $\begin{array}{l}\text { - Introduce vocabulary } \\
\text { - Prime schemata to familiarize students with the topic } \\
\text { - Add communicative element }\end{array}$ \\
\hline Focus on language & News article & $\begin{array}{l}\text { - Read current news topic } \\
\text { - Highlight vocabulary }\end{array}$ \\
\hline Focus on form & $\begin{array}{l}\text { Comprehension } \\
\text { check }\end{array}$ & $\begin{array}{l}\text { - Focus questions on comprehension and on particular } \\
\text { grammar / lexical patterns }\end{array}$ \\
\hline Report & Student opinions & - Students write their reaction to the news topic \\
\hline Review & Vocabulary quiz & $\begin{array}{l}\text { - Quiz students on topic words and common words } \\
\text { - Reinforce grammatical / lexical patterns }\end{array}$ \\
\hline
\end{tabular}

\section{Mode of Delivery}

As the content of the course was to be shared between classes at different universities, the authors decided to create their own course website common to all classes. Fortunately, there are now many web-based tools available for teachers to create online content for their classes. These are, for the most part, extremely user-friendly with a great deal of clear instruction and support for novice users. After discussing various options, the authors decided to use the blogging tool Wordpress, which enables users to create personal and private websites, upload 
materials, and administer access to the content. For these courses, the website would initially function as a medium through which students could gain access to the lesson content and materials, allowing them to prepare for the class as well as for later revision to prepare for quizzes and tests. This was a particularly important consideration, since learners can often experience anxiety or frustration when faced with the difficulties inherent in authentic texts such as news articles (Bacon \& Finneman, 1990). However, as Erbaggio et al. (2010) argued, by presenting the materials online for self-access, students have more control over the pace of language input by governing when and how they engage with the materials.

In addition, the authors wanted to explore the possibility of using the website as a forum for discussion of the news stories, enabling the final report stage of the task cycle. Most news websites now offer their readers the opportunity to comment on articles. Replicating this type of online activity was therefore considered to be an appropriate way of prompting students to write and discuss their opinions. This would aim to promote learning through a more considered, deeper engagement with the materials. As Erbaggio et al. (2010) pointed out, with reference to Carmean and Haefner (2002), when learning is "social, active, contextual, engaging, and student-owned," it enables students to internalize more of the knowledge and skills they have been taught, resulting in a "meaningful understanding of material and content" (as cited in Erbaggio et al., 2010, p. 30). An activity of this kind would also go some way towards tackling what the authors had previously perceived as Japanese students' reticence in class. Erbaggio et al. (2010), in a case study of the use of online materials, discovered that social activities requiring students to interact with each other, instead of with their teacher in class, elicited a greater level of participation from those who were more reluctant to speak up in class discussions.

Finally, it was decided that students should be able to post comments anonymously, giving them greater freedom and comfort to voice their opinions than would be possible in the classroom. It was also believed that they would have less inhibition when making mistakes, allowing for greater experimentation with language use and expression. In short, the website would, in the opinion of the authors, aim to shift the traditional balance of power in the language classroom where, according to McGrath (1998), teachers become facilitators and students become active learners.

To maximize student participation given the anonymous posting system, the authors decided to make student comments part of their assessment and instructed students to post one comment after each news story. These comments could be a reaction to the news story, a reaction to any of the other comments posted or a combination of both. At the end of each semester, students were required to compile an online portfolio of their comments (see Appendix B). These were then assessed by each teacher based on the quality of the comment, with regard to both the content and use of language.

\section{Student Use of the Website}

The course has now run for two semesters of 15 weeks and during that time, the authors have witnessed an impressive amount of student activity on the class website as represented in Table 2 . 


\section{Table 2}

Use of the Website

\begin{tabular}{|l|c|}
\hline Number of students & 62 \\
\hline Number of news stories & 15 \\
\hline Number of comments & 859 \\
\hline Average number of comments per story & 61 \\
\hline Average length of comment & 72 words \\
\hline
\end{tabular}

The average number of comments per story shows that almost all students wrote one comment for each story, as instructed. While some of the comments were very short, perhaps one or two sentences, others were very long and involved, resulting in an average of 72 words per comment. Shorter comments may have been due to time constraints or lack of interest in the story, while longer comments show that some stories were particularly engaging. A few website comments are given here (language errors included), together with the respective news story headline and commentary. Further examples of comments can be found in Appendix C.

\section{Obama Says Same-Sex Couples Should Be Able to Marry}

This is the first time to think of gay marriage for me. In Japan, it's the unrealistic ploblem yet. I suppose that gay couples' marriage should be admitted if they want to do, but I against adopting children. Because their children have no mother and that will cause many ploblems such as bullying at school, mental unrest etc. By the way, media says Mr. Obama's approval of such marriage is one of election campaigns. I'm interested in eligible voters' movement especially young people.

This comment draws attention to two points with relation to the authors' pedagogical aims in setting up the course. First, it is clear that the story has introduced a new topic to the student, engaging the student's curiosity with current events, a factor deemed necessary for motivation. Secondly, by addressing the issue of election campaigning and young people's voting intentions, the student demonstrates a meaningful understanding of the content and opens up the discussion to wider debate on the website.

\section{Japanese Losing Ability to Write Kanji Due to Emails}

I agree with $\mathrm{h}^{* * * * * * * *}$ 's and $\mathrm{r}^{* * * * * * *}$ 's idea. We Japanese should continue writing Kanji by hand as our traditional culture. In addition I have another reason for this. These days some people that we need not write Kanji by hand because of computers and smartphones. However I think that we need write Kanji by hand to grow intelligence since we are children.

This comment demonstrates the development of the online discussion. By drawing on previous student comments, this student has created a dialogue between members that highlights the social aspect of the learning process as referred to by Erbaggio et al. (2010) in the previous section. 


\section{Nurse at Center of Duchess of Cambridge Hoax Call Dies in Case of Suspected Suicide}

I was very shocked about this news story. Duchess of Cambridge must have been shocked as well. First of all, I couldn't believe the insensitivities of these DJs. The nurses in the hospital must have been busy with the pregnancy of Kate, and it's too rude to dupe people in such a situation. In addition, it was written that one of the DJs boasted what they had done and it's so ridiculous. They might truly apologize as they apprehended the gravity of the situation, but they have to know it's too late. I hope they never repeat the mistake again.

Here the student has begun to experiment with the vocabulary and expressions introduced in the news story. Highlighted words from the story were dupe and boast. There is also evidence of use of vocabulary (ridiculous) from a previous story. This comment and others like it show that students are noticing lexical items and starting to acquire them through incorporation into their opinions on the website.

\section{Feedback From Students About The Course}

At the end of the academic year, a simple questionnaire in Japanese was administered to all students to acquire some initial feedback about their opinions of using the materials and the course website. Students were asked how their experience of the course had an impact on their language learning and motivation. A selection of comments translated from the original Japanese are represented in Appendix D and briefly discussed here. Firstly, it seems that using authentic news-based materials was, in the words of one student, "a very good idea . . By learning about news in the world, I could not only study English but also learn about foreign countries, people, and cultures." Moreover, providing materials online was a welcome novelty to some: "writing a blog was very new and interesting," and "the course was very different from the classes in high school, and I found it very new." This also helped engage some to study more often; as one student mentions, "To be prepared for the Monday class, I had to read English over the weekend. Because of this, I was able to study English more regularly." More importantly, with respect to the pedagogical aims of the course, many of the comments seem to indicate that students had increased their motivation through writing their opinions on the class website. In particular, the social aspect of learning seems to have been a success in this regard: "It was good and motivating for me to compare my opinion with other students' ones." It can also be seen that students were inspired to pay more attention to their use of English: "Because the comments were read by other students, I tried to express my opinions in an easily understood way, which I think helped me to improve my English," and, "Even though we exchanged opinions anonymously, the comments were read by other students, which helped me to keep the motivation and to be more careful about grammar, etc." These comments clearly demonstrate that student writing on the website helped facilitate the report stage of the task cycle that aims to focus learners on producing more considered, accurate language.

While many of the comments show how students engaged positively with the course and materials, there are also those who mentioned that they were still struggling with the high level "technical" language needed, and wanted greater clarification and feedback on their use of English. To address these points, the authors need to consider ways in which advice to students can be incorporated into the course without encroaching on the freedom of the blog writing. With a large corpus of learner English now in place in the form of comments on the class website, however, it is hoped that further research into students' use of language will be of significant benefit in the planning and materials design of subsequent news-based courses delivered online. 


\section{Author Note}

Tim Marchand, English Language Program, J. F. Oberlin University, Machida, Tokyo, Japan. Benedict Rowlett, Department of Commerce, Chuo University, Hachioji, Tokyo, Japan.

Benedict Rowlett is now at the Foreign Language Center, Tokai University, Kanagawa, Japan.

This paper is based on a presentation given by Benedict Rowlett at CamTESOL 2013. The authors wish to give their thanks to Sumie Akutsu at J. F. Oberlin University who translated the student comments from the questionnaire into English.

Correspondence concerning this article should be addressed to Benedict J. L. Rowlett, Foreign Language Center, Tokai University 4-1-1 Kitakaname, Hiratsuka City, Kanagawa, 259-1252, Japan. E-mail: benedictrowlett@me.com 


\section{References}

Alm, A. (2006). CALL for autonomy, competence and relatedness: Motivating language learning environments in Web 2.0. The JALT CALL Journal, 2(3), 29-38. Available at http://journal.jaltcall.org/articles/2_3_Alm.pdf

Anderson, F. (1993). The enigma of the college classroom: Nails that don't stick up. In P. Wadden (Ed.), A handbook for teaching English at Japanese colleges and universities (pp. 101-110). New York, NY: Oxford.

Arena, C., \& Jefferson, C. T. (2008). Blogging in the language classroom: It doesn't "simply happen." TESL-EJ,11(4), 1-7. Retrieved from http://tesl-ej.org/ej44/a3.pdf

Bacon, S. M., \& Finneman, M. (1990). A study of the attitudes, motives and strategies of university foreign-language students and their disposition to authentic oral and written input. Modern Language Journal, 74(4), 459-473. http://dx.doi.org/10.2307/328520

Blake, R. J. (2008). Brave new digital classroom: Technology and foreign language learning. Washington DC: Georgetown University Press.

Brown, H. D. (2006). Principles of language learning and teaching. Englewood Cliffs, NJ: Prentice Hall Regents.

Butler, Y. G., \& lino, M. (2005). Current Japanese reforms in English language education: The 2003 "Action Plan." Language Policy 4(1), 25-45. http://dx.doi.org/10.1007/s10993004-6563-5

Carney, N. (2007). Language study through blog exchanges. In Thomas, M. (Ed.), Proceedings of the $1^{\text {st }}$ International Wireless Ready Symposium: Podcasting Education and Mobile Assisted Language Learning, NUCB Graduate School, 24 March 2007. Retrieved from http://wirelessready.nucba.ac.jp/Carney.pdf

Chun, D. M. (2008). Foreword. In R. J. Blake, Brave new digital classroom: Technology and foreign language learning (pp. xi-xii). Washington DC: Georgetown University Press.

Doyon, P. (2000). Shyness in the Japanese EFL class. The Language Teacher, 24(1), 10-11.

Erbaggio, P., Gopalakrishnan, S., Hobbs, S., \& Liu, H. (2010). Enhancing student engagement through online authentic materials. International Association for Language Learning Technology 42(2). Retrieved from http://www.iallt.org/iallt_journal/enhancing_student_engagement_through_online_mate rials

Graves, K. (2000). Designing language courses: A guide for teachers. Boston, MA: Heinle and Heinle.

Johnson, A. (2004). Creating a writing course utilizing class and student blogs. The Internet TESL Journal, 10(8). Retrieved from http://iteslj.org/Techniques/Johnson-Blogs/

Kung, S.-C., \& Chuo, T.-W. (2002). Students' perceptions of English learning through ESL/EFL websites. TESL-EJ, 6(1), 1-14. Retrieved from http://tesl-ej.org/ej21/a2.html

Marchand, T. (2011). Product placement in a process syllabus: Designing a university course in Current Affairs English. In A. Stewart (Ed.), JAL T2010 Conference Proceedings. Available at http://jalt-publications.org/proceedings/articles/1119-product-placement-processsyllabus-designing-university-course-current-aff

Marchand, T. (2012). Reticence in the classroom: Examples, causes, and suggestions for improvement. Obirin Today, 12, 159-180.

Lahuerta Martínez, A. C. (2003). A study of the relationship between Spanish undergraduates' motivational factors and foreign language achievement. Revista de Lenguas para Fines Especificos, 9/10, 115-138. Available from http://acceda.ulpgc.es/bitstream/10553/4694/1/0233536_00009_0007.pdf

McGrath, B. (1998). Partners in learning: Twelve ways technology changes the teacher-student relationship. T.H.E. Journal, 25(9), 58-61.

Obama says same-sex couples should be able to marry. (2012, May 9). BBC. Retrieved from http://www.bbc.co.uk/news/world-us-canada-18014102 
Rogers, C. V., \& Medley, F. W., Jr. (1988). Language with a purpose: Using authentic materials in the foreign language classroom. Foreign Language Annals, 21(5), 467-478. http://dx.doi.org/10.1111/j.1944-9720.1988.tb01098.x

Williams, C. (1994). Situational behavior and the EFL classroom in Japan. The Language Teacher, 18(5), 10-11. 


\section{Appendix A \\ Example Lesson Materials \\ News Based English - Political News}

\section{Warm-Up 1a: Countries where same-sex marriage is legal}

Which countries do you think have already legalized same-sex marriage? Write your ideas in the table below (number of countries in each area).

\begin{tabular}{|l|l|l|l|}
\hline Europe (7) & Africa (1) & North America (1) & South America (1) \\
\hline & & & \\
& & & \\
\hline
\end{tabular}

\section{Warm-Up 1b: What rights should same sex couples have?}

Read the rights below and indicate whether you think same-sex couples should have them.

Then ask your partner their opinion. Support your opinions with reasons.

\begin{tabular}{|c|c|c|}
\hline Rights & You & Your Partner \\
\hline $\begin{array}{l}\text { 1. To live together } \\
\text { 2. To get married } \\
\text { 3. To get tax benefits } \\
\text { 4. To make medical } \\
\text { decisions for their partner } \\
\text { 5. To adopt children }\end{array}$ & & \\
\hline
\end{tabular}

\section{Warm-Up 2: Predicting the news}

\section{Obama says same-sex couples should be able to marry}

1. TRUE / FALSE: Read the headline. Guess if a-h below are true (T) or false (F).

a. President Obama supports same-sex marriage. $T / F$

b. $50 \%$ of Americans support same-sex marriage. $T / F$

c. More Americans support gay marriage than last year. $T / F$

d. Mr Obama's government has increased other rights for gay people. $T / F$

e. Mr Obama reached his decision after seeing committed gay relationships among members of his family. $T / F$

f. Many US states have already passed laws banning same-sex marriages. $T / F$

g. Mitt Romney, who is running for president against Mr Obama, also supports gay marriage. $\quad T / F$

h. Mr Romney believes that gay people should have the right to visit their partners in hospital. $\quad T / F$

2. SYNONYM MATCH: Match the following synonyms from the article.
1. hedging
a. law
2. back
b. faithful
3. administration
c. support
4. repeal
d. evasion
5. act
e restrict
6. monogamous
f. alteration
7. constrain
g. dividing
8. amendment
h. suitable
9. polarizing
i. abolish
10. appropriate
j. government 


\section{Obama says same-sex couples should be able to marry}

("Obama Says," 2012)

WASHINGTON - US President Barack Obama has ended months of hedging on the issue of gay marriage by saying he thinks same-sex couples should be able to wed. He has become the first sitting US president to back gay marriage. A recent poll suggested that $50 \%$ of Americans were in favour of legalising gay marriage - a slightly lower proportion than last year - while $48 \%$ said they would oppose such a move.

In an interview with ABC News Mr Obama said, "I've concluded that for me personally it is important for me to go ahead and affirm that I think same-sex couples should be able to get married." He pointed to his administration's commitment to increasing rights for gay citizens. He gave as an example his administration's repeal of the military's "don't ask, don't tell" policy* and said they had dropped support for the Defense of Marriage Act.

He said that he wanted to make his views clear after seeing gay members of his own staff who were in "incredibly committed monogamous relationships", and service personnel who felt constrained by not being able to wed. His comments come a day after North Carolina approved a constitutional amendment effectively banning same-sex marriage or civil unions. The Obama campaign had opposed that measure, which was passed with $61 \%$ in favour and $39 \%$ against. In the US, 31 states have passed constitutional amendments or legislation against same-sex marriage.

Meanwhile, Mr Romney set the stage for an election year clash over the polarising social issue by saying he was against gay marriage. The former Massachusetts governor told a Fox News reporter: "I do not favour marriage between people of the same gender, and I do not favour civil unions if they are identical to marriage other than by name. "My view is the domestic partnership benefits, hospital visitation rights, and the like are appropriate but that the others are not."

${ }^{*}$ A policy in which members of the military had to keep silent about their sexuality at the risk of losing their jobs

Vocabulary in bold Vocabulary underlined Vocabulary in italics
$=$ verbs

$=$ nouns

$=$ adjectives

cohesion

he $=$

president $=$

they $=$

move $=$

$\mathrm{me}=$

example = they $=$

who $=$

who $=$

which $=$

governor $=$

they $=$

the like = 


\section{Comprehension Check}

Student A's Questions (Do not show these to Student B)

1a. How did you feel when you read the headline?

2a. Who was the first sitting US President to back gay marriage?

3a. What percentage of Americans oppose gay marriage?

4a. Why did Mr Obama want to make his views on gay marriage clear?

5a. How many states have also passed laws that ban gay marriage?

6a. What are Mitt Romney's views on gay marriage?

7a. Why do you think gay marriage is such a big issue in the US?

8a. With B, check the cohesion to the right of the article. What do all the words / phrases refer to?

9a. With B, go back to the true or false sentences. Now check the synonyms 1-10 again.

10a. Was this news: too difficult / okay / too easy for you?

Student B's Questions (Do not show these to Student A)

1b. Did you think this article was interesting?

2b. What percentage of Americans support gay marriage?

3b. What was the American military's "don't ask, don't tell" policy?

4b. Which state recently approved a law that bans gay marriage?

5b. Who is Mitt Romney?

6b. What rights for gay people does Mr Romney approve of?

7b. Do you think that gay marriage will ever be legal in Japan? Why? Why not?

8b. With $\mathrm{A}$, check the cohesion to the right of the article. What do all the words / phrases refer to?

9b. With A, go back to the true or false sentences. Now check the synonyms 1-10 again.

10b. Was this news: too difficult / okay / too easy for you?

My thoughts: 


\section{Appendix B}

\section{Portfolio of Comments for Assessment (Online Form)}

Please fill out the portfolio questions below and send it to me (" ${ }^{*}$ required question)

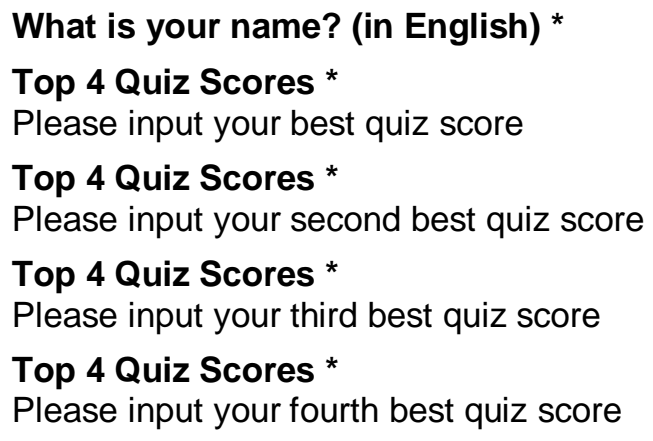




\title{
Appendix C \\ Sample of Student Comments on the News Story "Obama Says Same Sex Couples Should Be Able to Marry"
}

\begin{abstract}
In my opinion, same-sex couples should be able to get married. Of course, I know there are various religions in the United States and some people think it is a bad thing. I think it is difficult that ALL citizens agree with guy marriage. There are lots of opinions in the country. But I think "the government" should not ban the marriage. If it ban the marriage because they are same-sex, does the government disturb the citizen's freedom of the marriage? If they love with each other and want to wed, the government can't ban the marriage.
\end{abstract}

I don't agree with Obama. It's true that many form of love exist and I don't condemn itself, but Gay is ethically problematic.

They can't leave offspring, so government shouldn't admit officially. That's the reason why I disagree with same sex couple marriage.

I'm in favor of gay marriage. The most important thing in democracy is to respect personal thoughts. Besides marriage is one of the most important event in our life. Therefore, gay marriage should be admitted.

I think homosexuality should be permit.

For my part, at present, I can't agree to the same-sex marriage. It is said some people are afraid of being loved by gay people, and also said the birthrate in the country may decline. Both of them I ' $m$ afraid too. On the contrary, however, these view may have some misconceptions. And history tells us that there were many gay people in ancient Greece and the Warring States period of Japan, which indicates the gay rights is not necessarily the problem specific to today.

Moreover,the jaoaneseTV programes show that there are many gay people who is proud of themselves. The more japanese people know them, the more they may be tolerate to the gay. In conclusion, now i'm against gay marriage, but in the future, I'll change my thoughts if I have more information about gay people.

When I read this article, I was very surprised, and thought this is very good news. In many countries and areas, same sex couple are not recognized by the public. Obama did so courageous decision. I wish this Obama's new method succeed. And,I think that japan also have to recognized gay's marriage right.

This is the first time to think of gay marriage for me. In Japan, it's the unrealistic ploblem yet. I suppose that gay couples' marriage should be admitted if they want to do, but I against adopting children. Because their children have no mother and that will cause many ploblems such as bullying at school, mental unrest etc. By the way, media says Mr. Obama's approval of such marriage is one of election campaigns. I'm interested in eligible voters' movement especially young people.

I agree with Obama's opinion. However same sex marry is not accepted in Japan, same sex marry is proper. It is because they have right to get married with a lover.

I favor gay marriage. It is one of the human rights.

I agree with homosexual marriages. I think prohibiting gay marriages runs counter to human rights. We investigate gay people's human rights with respect to marriage. In my opinion, happiness possessing rights, equality rights and privacy rights are violated in this scenario. The entitlement of happiness possessing rights is already guaranteed by first amendment in Virginia Bill of Rights. It is stipulated in 13rd amendment of constitution of japan too. Freedoms without distinction of any kind of status are guaranteed by Universal Declaration of Human Rights. The constitutions of most countries guarantee this right too. And in 2003, Texas Supreme Court judged that the prohibition of homosexual activity is against the right of privacy. Actually, many countries like Portugal, Belgium, The Netherlands, Spain, Sweden, Norway, Iceland, South Africa, Canada, Argentina permit same sex couple marriage. In fact the Netherlands have law of anti-distinction. According to this law, gays have the same rights as heterosexual couples. These are reason why I agree with same sex couple marriage. 
I disagree with Obama's opinion. Gay must be prohibited strictly.

There is only one reason to think so. Gay is not correct in ethics. A living thing in the earth have to leave offspring.

As most people here say, I agree with legalising gay marriage. Whether you love same-sex or opposite sex depends on you. It is wrong that nation prohibits guy marriage. However as $\mathrm{h}^{\star \star \star \star \star \star \star \star \star}$ points out, whether same-sev couple should be allowed to adopt children or not is big and complicated question. Same-sex couple should be allowed right same as opposite-sex couple but considering children, children should be brought up by mother and father.

I think same sex marriage should be legal. Same sex couple just love each other so I dont want them to give up to get marry because of the gender. But I think same sex couple should not have the right to adopt children unless the children understand about it.

I think it is individual freedom. Although I'm against to this. I expect that permitting same-sex marriage will cause a lot of social problems.

I believe that same-sex couple should be equal with others. As $\mathrm{y}^{\star \star \star \star \star \star \star}$ say, I think the religious is the matter for them. Christian don't allow the same-sex marriage, and that is why same-sex couples are difficult to marriage. I know the religious is important for them, however, it is strange that human don't have same equal right. We are all equal before the low. I strongly support samesex couple. 


\section{Appendix D \\ Selection of Responses for the Questionnaire Item: \\ Please write any thoughts you may have about writing on a news-based blog for this course in terms of improving your English-language skills and motivation.}

The question and comments have been translated from the original Japanese.

\begin{tabular}{|c|c|}
\hline & 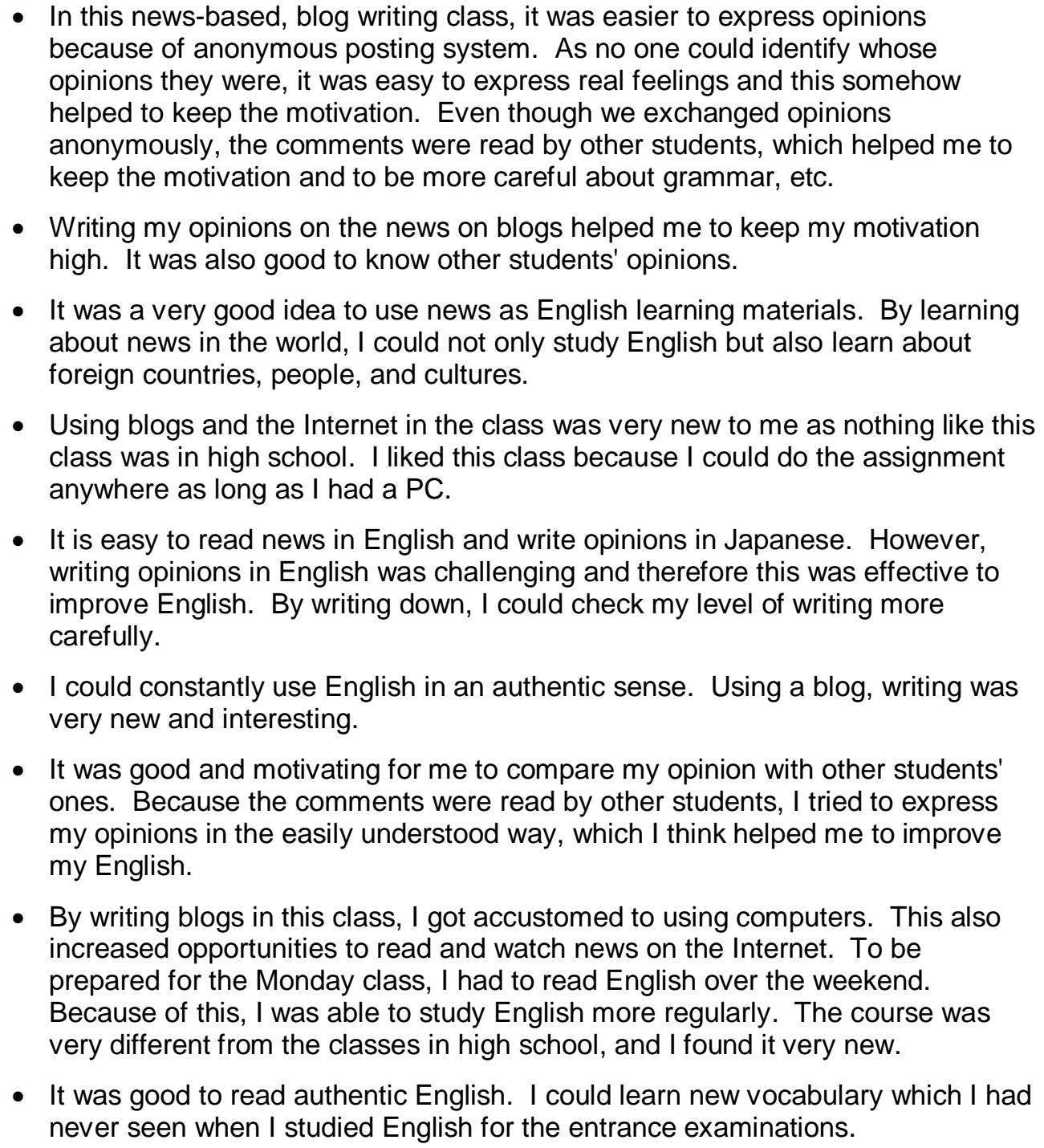 \\
\hline $\begin{array}{l}\text { Somewhat } \\
\text { Negative } \\
\text { Feedback }\end{array}$ & $\begin{array}{l}\text { - I didn't find blog writings easy to use and not necessarily motivating to study. } \\
\text { However, I found the class and the learning interesting and meaningful } \\
\text { especially because I could read a lot of current news. I would like to continue to } \\
\text { read news in English in order to improve my English. } \\
\text { - Using news was effective but at the same time was very difficult because of } \\
\text { technical vocabulary. I personally preferred to write on the paper and hand it in. } \\
\text { However, it was interesting to be able to read other students' opinions. } \\
\text { - I was sometimes not sure about my grammar. I would like my English checked } \\
\text { from time to time. } \\
\text { - It was difficult to keep up with the high level of English in this class. }\end{array}$ \\
\hline
\end{tabular}

